\title{
SONYOL MEGAL-MEGOL
}

Oleh : Sekar Ayu Oktaviana Sari

Email: sekarayu_os@yahoo.com

Pembimbing Tugas Akhir: Prof. Dr. Y. Sumandiyo Hadi, S.ST., S.U. dan

Dra. Erlina Pantja S, M,Hum.

\section{RINGKASAN}

Tulang adalah penopang tubuh, tanpa tulang tubuh tidak akan bisa berdiri tegak. Salah satu tulang yang berfungsi sebagai tumpuan badan ketika duduk disebut dengan tulang panggul atau pangkal paha di sebelah belakang. Keunikan yang terjadi ketika tulang panggul digerakkan dengan cara memutar atau bergerak ke kanan dan ke kiri akan berakibat yang disebut dengan istilah Jawa yaitu megal-megol atau pantat yang bergerak ke kanan dan ke kiri.

Melihat fenomena di atas muncul ide untuk menciptakan sebuah karya tari yang bersumber dari gerakan otot bagian panggul. Penata memiliki postur tubuh yang menonjol di bagian panggul, sehingga tampak kurang proposional, hal ini menjadi menarik sehingga terinspirasi untuk menciptakan sebuah koreografi kelompok. Karya tari ini akan fokus pada gerakkan seputaran panggul. Gerakan tersebut sangat menarik karena memiliki keunikan tersendiri. Permainan panggul yang digerakan secara vibrasi mengakibatkan pantat bergetar, sehingga gerakan tersebut menjadi salah satu gerak yang akan dikembangkan.

Karya koreografi Sonyol Megal-Megol ini melibatkan dua puluh delapan orang penari perempuan, dengan delapan penari inti dan duapuluh penari pendukung. Adapun jumlah penari sebagai pertimbangan untuk komposisi koreografi, sedangkan untuk pemilihan jenis kelamin karena yang memiliki panggul atau pantat besar dominan perempuan. Karya koreografi mengangkat konsep tentang salah satu bagian tubuh yang berfungsi sebagai tumpuan badan ketika duduk yaitu panggul atau pantat. Musik yang akan digunakan adalah play recorder.

kata kunci : Sonyol, Panggul, Megal-Megol

\section{ABSTRACT}

Skull is the supporting of the body, and without it body will not be able to stand upright. Skull which has the function to support the body when in sit position is called hip. When hip is being moved to the right and left side or by the curning way, it will create a movement named megal-megol(the bottom move to the right and left side) in javanese analogy.

Look at the phenomenon stated above, an idea to create a dance work based on the movement muscle in hip arises. Choreographer has a prominent hip therefore it looks less proportional. This interisting fact inspires choreographer to create a group dance. This dance focuses on hip movement which has uniqueness inside it. Hip which is being moved vibratory causes a movement on the bottom, therefore this a dance that will be developed.

Sonyol Megal-Megol choreography involves twenty eight female dancers consist of eight main dancer and twenty supporter dancer. Choreography composition considers the number of dancers. The reason of choosing female as the dancer is because female more likely to have a big hip. The concept of the choreography come up from a part of the body which is used to be a body supporting when in a sit position called hip. The music is being played by recorder.

\section{Keyward: Sonyol, Hip, Megal-Megol}




\section{PENDAHULUAN}

\section{A. Latar Belakang Penciptaan}

Gerak merupakan unsur utama dalam sebuah tarian. Gerak tari merupakan serangkaian gerakan anggota tubuh yang memiliki nilai estetis sehingga dapat dinikmati oleh orang lain. Gerakan tari yang indah membutuhkan proses pengolahan atau penggarapan terlebih dahulu, pengolahan unsur keindahannya bersifat stilisasi dan distorsi. Gerak stilisasi mempunyai arti gerak yang telah mengalami proses pengolahan yang mengarah pada bentuk-bentuk yang indah, sedangkan arti kata gerak distorsi adalah pengolahan gerak melalui proses perombakan dari aslinya dan merupakan salah satu proses stilasi.

Gerak dapat diperolah dari eksplorasi atau penjelajahan; Eksplorasi adalah tahap awal proses koreografi, yaitu suatu penjajagan terhadap objek atau fenomena dari luar dirinya, suatu pengalaman untuk mendapatkan rangsangan, sehingga dapat memperkuat daya kreativitas. Eksplorasi termasuk memikirkan, mengimajinasi, merenungkan, merasakan dan juga merespon objek-objek atau fenomena alam yang ada ( Alma M. Hawkins. Creating Through Dance, Univercity of California: Los Angeles. Dialih bahasakan oleh Y. Suamandiyo Hadi, 1990, Mencipta Lewat Tari, ISI Yogyakarta: Yogyakarta.p 70. ). Penggalian gerakan pada tubuh ditunjang untuk pemenuhan penyampaian pesan. Gerakan tari dihasilkan dari gerakan kepala, pundak, tangan, torso, panggul, dan kaki.

Gerak-gerak panggul atau pantat kadang kala dianggap gerak yang fulgar jika digerakkan secara berlebihan. Hal itu disebabkan mainset atau konstruksi pola pikir masyarakat Jawa erat kaitannya dengan agama khususnya Islam. Menurut Syaikh Muhammad al-Albani menjelaskan bahwa dalam sebuah tarian biasanya disertai gerakan pantat dan sejenisnya yang bisa menimbulkan syahwat, maka hukumnya menjadi terlarang (Syaikh Muhammad Nashiruddin Al-Albani. Majalah
Al-Ashalah 8/15 Jumadil Akhir 1414 hal.73. Fatwa Fadhilatus Syaikh Muhammad Nashiruddin Al-Albani Terjemahan Muhaiman Abu Najiah, Semarang: Abiyah Pratama 1955 ). Gerakan pantat dalam istilah Jawa sering disebut megal-megol yaitu pantat yang bergerak ke kanan dan ke kiri memiliki konotasi negatif, tetapi dalam pengalaman koreografi, gerakan ini melahirkan kesan sebagai sebuah bentuk yang mempunyai nilai estetis tertentu dan dapat dirasakan sebagai pengalaman seni yang sangat unik. Pada umumnya ketika kebanyakan orang menari tidak ada salah satu fokus atau dominan anggota tubuh tertentu. Karya koreografi ini dominan pada gerakan panggul atau tipe studi gerak panggul sehingga muncullah gerak panggul atau pantat melingkar, patah-patah, liukan, vibrasi dan kendo-kenceng atau contraction and release .

Panggul terdiri dari bagian keras yang dibentuk oleh tulang, bagian yang lunak dibentuk oleh otot. Dengan adanya struktur otot pada tubuh manusia, terjadilah pergerakan seperti peristiwa mata berkedip, menelan dan kulit bergetar, kesemuanya itu merupakan hasil kerja otot. Menurut Setiadi dalam buku berjudul Anatomi dan Fisiologi Manusia, otot tubuh dibagi dalam beberapa golongan sebagai berikut (Setiadi. Anatomi dan Fisiologi Manusia. Jakarta: Graha Ilmu 2007. Hal 270 )

\section{Otot bagian kepala}

2. Otot bagian leher

3. Otot bagian dada

4. Otot bagian perut

5. Otot bagian bahu dan lengan

6. Otot bagian panggul

7. Otot bagian anggota gerak bawah.

Dari uraian di atas gerakan tari atau koreografi ini berfokus pada otot panggul. Otot bagian panggul terdiri dari tulang panggul atau columna vertebralis menuju ke pangkal paha, 
sedangkan sebelah belakang bagian luar terdapat muskulus gluteus maksimus, merupakan otot terbesar yang terdapat di sebelah luar panggul yang membentuk pantat.

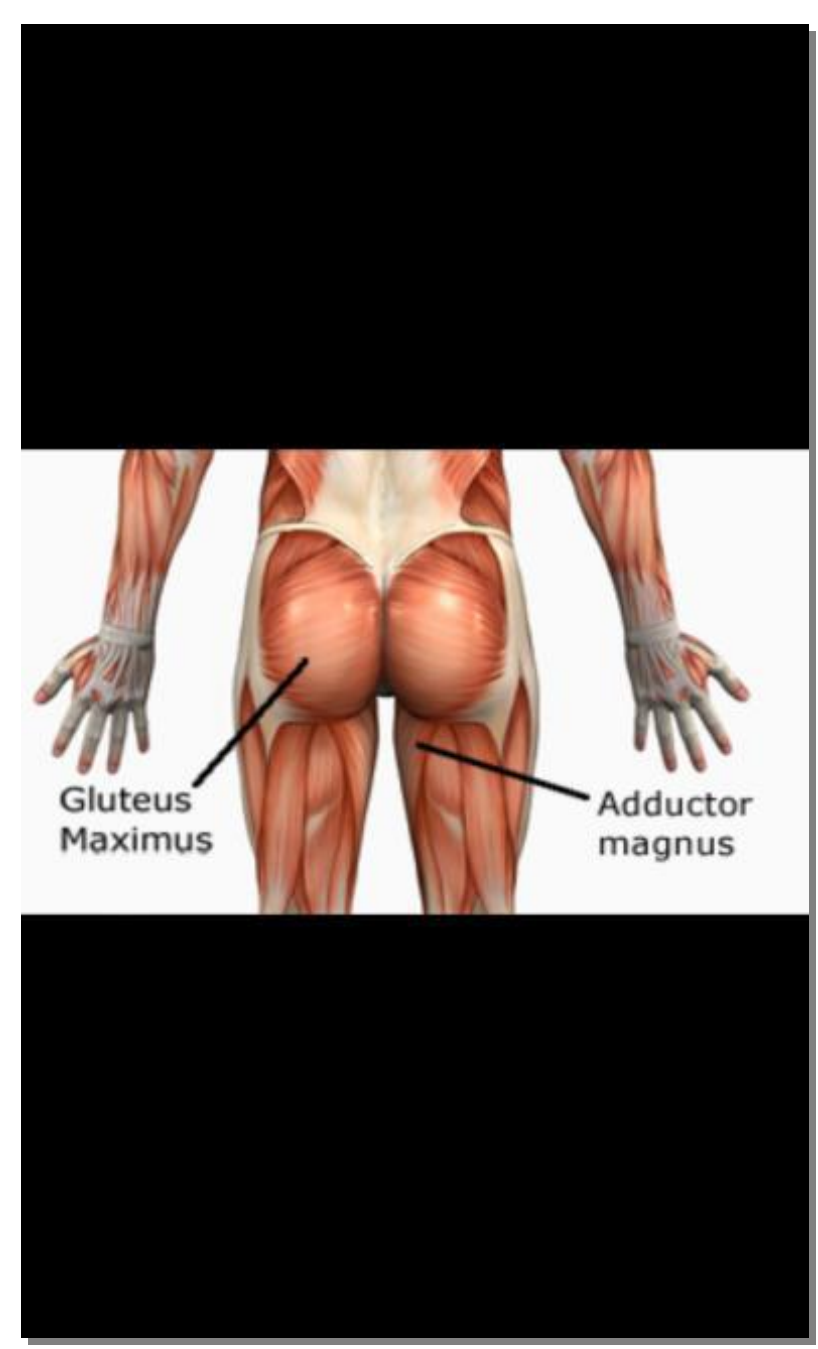

Gambar.1 Gambar otot bagian panggul dalam tubuh manusia.

Melihat fenomena di atas muncul ide untuk menciptakan sebuah karya tari yang bersumber dari gerakan otot bagian panggul dan gerak panggul. Penata memiliki postur tubuh yang menonjol di bagian panggul, sehingga tampak kurang proposional, hal ini menjadi menarik sehingga terinspirasi untuk menciptakan sebuah koreografi kelompok dengan tipe tari studi.

Karya tari ini akan fokus pada gerakan seputaran panggul. Gerakan tersebut sangat menarik karena memiliki keunikan tersendiri.
Permainan panggul yang digerakan secara vibrasi mengakibatkan pantat bergetar, sehingga gerakan tersebut menjadi salah satu gerak yang akan dikembangkan.

Dalam penggarapannya, akan dikembangkan atau dicari teba gerak dari gerak megal-megol. Gerak tersebut akan disesuaikan dengan ketubuhan dan pengalaman dalam berkesenian. Kemudian akan dikomposisikan agar menjadi sebuah karya tari yang dinamis, seperti gerakan panggul memutar, vibrasi, liukan, kendokenceng atau contraction and release .

Karya tari yang diciptakan mengeksplor kekuatan panggul dengan memperhatikan prinsip koreografi seperti ruang, waktu, tenaga. Penari yang akan digunakan berjumlah delapan orang perempuan yang memiliki postur tubuh kurang lebih seperti penata atau yang memiliki panggul besar dan menggunakan setting panggung berupa level atau trap. Kostum yang digunakan kain yang lentur dan berwarna kulit.

Dari latar belakang diatas memunculkan pertanyaan-pertanyaan kreatif sebagai berikut :

a. Bagaimana memvisualisasikan anggota tubuh dominasi panggul dengan delapan penari inti dan duapuluh penari pendukung di atas panggung proscenium stage?

b. Bagaimana menghadirkan atau mengolah gerakan otot panggul sehingga membentuk koreografi ?

c. Bagaimana menvisualisasi anggota tubuh dominasi panggul dengan motivasi yang lebih komikal ?

Dari pertanyaan-pertanyaan kreatif di atas memunculkan rumusan ide penciptaan karya koreografi dengan judul Sonyol MegalMegol. Karya koreografi yang terinspirasi dari melihat dan memperhatikan kebanyakan orang yang menimbulkan efek keunikan yaitu gerak yang sering disebut megal-megol. Hal tersebut dianggap menarik sehingga terciptalah untuk 
membuat koreografi kelompok dengan tema pengolahan gerak patah-patah dan melingkar pada panggul serta dikemas dalam tipe tari studi.

\section{B. Rumusan Ide Penciptaan}

Karya yang terinspirasi dari cara atau gaya orang berjalan pada umumnya sehingga berakibat gerak yang disebut megal-megol atau pantat yang bergerak ke kanan dan ke kiri. Bermodalkan postur tubuh yang tidak proposional atau tubuh menonjol di bagian pantat, merupakan anugerah tersendiri. Karya koreografi ini menampilkan beberapa pengolahan gerakan panggul dan pantat, gerak-gerak yang dimunculkan seperti liukan, vibrasi, patah-patah, melingkar, tekanan dan mengalun.

\section{Tujuan dan Manfaat Penciptaan}

\section{Tujuan}

a) Mencoba mengembangkan motif gerak tari megal-megol dengan ketubuhan penari.

b) Mengolah kreativitas untuk terus mencari teba gerak dari motif tersebut agar dapat menjadi komposisi tari yang dapat dinikmati semua orang.

\section{Manfaat}

a) Manfaat bagi koreografer sendiri yaitu dapat membuat suatu tarian yang hanya didasari dengan gerak dominasi pantat atau gerak megal-megol.

b) Manfaat bagi mahasiswa penciptaan tari bisa mendapatkan referensi lebih banyak ketika membuat sebuah karya tari.

\section{Tinjauan Sumber}

\section{Sumber Pustaka}

Buku Berjudul Koreografi: Bentuk, Teknik dan Isi oleh Y. Sumandiyo Hadi. Buku tersebut memberikan pengetahuan penata dan kontribusi karya koreografi ini pengertian koregrafi, gerak, ruang dan waktu sebagai elemen dasar koreografi. Tentunya buku ini sangat membantu penata dalam proses penggarapan karya koreografi ini dalam memahami elemen dasar pendukung koreografi, seperti ruang, waktu dan aspek gerak (tenaga) dalam penggunaan arah hadap, permainan level, dan aksi.

\section{Sumber Karya}

Dalam website http://www.youtube.com/ penata banyak menemukan acuan berupa video antara lain International Summer Bellydance Festival 2014 karya tari dari Amira Show Group. Hal tersebut menjadi pijakan dasar dalam penggarapan karya tari Sonyol Megal-Megol yang didominasi gerakan panggul dan pantat.

DVD "Yalla Habibi Belly" karya Trinh Tuyen (1990). Dari DVD ini penata mendapatkan banyak inspirasi gerak megalmegol, vibrasi dan stakato yang ritmis dan dinamis. Pada gerak-gerak panggul ini dimanfaatkan sebagai sumber pengolahan gerak dalam garapan tari Sonyol Megal-Megol.

\section{Sumber Lisan}

Pangkuyhona, 34 tahun, Alumni Universitas Negri Yogyakarta Jurusan Sastra jawa. Wawancara dilakukan pada hari Jumat tanggal 25 September 2015 di pendopo Tejokusumo Universitas Negri Yogyakarta. Yhona, panggilan sehari-hari, merupakan salah satu teman terdekat penata yang sering melakukan kegiatan seni teater Jawa bersama. Banyak informasi yang didapat, salah satunya mengenai bahasa prokem atau bahasa walikan.

\section{KONSEP PENCIPTAAN TARI}

\section{A. Kerangka Dasar Pemikiran}

Berawal dari melihat dan memperhatikan kebanyakan orang ketika berjalan kemudian memunculkan keunikan yaitu gerak pantat yang bergerak kekanan dan kekiri atau dalam bahasa Jawa disebut gerak megal-megol gerakan ini didukung dengan postur tubuh yang tidak proposional atau memiliki panggul besar dan mampu menggerakkan otot bagian pantat yang disebut 
otot muskulus gluteus maksimus sesuai irama. Gerakan otot pantat tersebut tidak semuanya orang mampu melakukannya sehingga perlu pelatihan khusus. Gerak megal-megol menjadi gerak dasar yang kemudian akan dikembangkan sesuai dengan kreativitas dan pengalaman tari tentang pengembangan gerak yang berkaitan dengan aspek ruang, waktu dan tenaga. "Sonyol Megal-Megol" merupakan karya lanjutan dari karya "Sonyol". Maka, pencapaian aspek teknik dan bentuk yang sudah dijadikan pertimbangan utama untuk tetap mendapatkan bentuk baru. Koreografi ini termasuk koreografi kelompok dengan dua puluh delapan penari putri, ke delapan penari putri tersebut memiliki porsi gerak yang lebih banyak dibanding dengan dua puluh penari putri lainnya, sedangkan penari dua puluh tersebut bergerak hanya di bagian klimaks atau akhir karya tari ini.

\section{B. Konsep Dasar Tari}

\section{Rangsang Tari}

Rangsang Idesional karena terinspirasi dari pengalaman pribadi yang selalu mendapat sapaan tentang postur tubuh yang berlebihan terutama di bagian panggul dan mempunyai kelebihan bisa menggerakkan otot bagian panggul yang membentuk pantat, yang bernama muskulus gluteus maksimus, kemudian berfikir untuk mengolahnya ke dalam bentuk karya tari dengan mengembangkan gerakan seperti patah-patah, liukan dan vibrasi dan kendo-kenceng atau contraction and release.

\section{Tema Tari}

Tema koreografi kelompok ini adalah pengolahan gerak panggul vibrasi, patah-patah dan melingkar pada panggul.

\section{Judul Tari}

Sonyol berasal dari bahasa prokem yang dikenal juga dengan istilah bahasa gaul yang artinya pantat, sedangkan megal-megol memiliki arti pantat yang bergerak ke kanan dan ke kiri. Jika disimpulkan arti kata dari
Sonyol Megal- Megol yaitu pantat yang bergerak ke kanan dan ke kiri.

\section{Bentuk dan Cara Ungkap}

a. Tipe Tari

Tipe tari yang digunakan dalam karya koreografi ini adalah tipe studi dan komikal.

b. Mode Penyajian

Mode penyajian dalam karya ini
menggunakan representasional, dengan gerak-gerak yang akan dimunculkan adalah gerakan "megalmegol".

\section{KONSEP GARAP TARI}

\section{Gerak Tari}

Gerak dasar yang digunakan karya tari Sonyol Megal-Megol adalah gerak dengan dominasi megal-megol. Bentuk gerak megalmegol tersebut diolah dan dikembangkan dengan gerak liyukan, putaran, patah-patah atau vibrasi dan kendo-kenceng atau contraction and release pada panggul dan digarap sesuai dengan kreativitas dan pengalaman tari yang berkaitan dengan aspek ruang, waktu dan tenaga. Gerak yang dihadirkan adalah gerak-gerak dinamis yang tidak jauh dari tema karya.

\section{Penari}

Dalam penciptaan karya tari yang bertajuk koreografi kelompok ini digunakan dua puluh delapan orang penari perempuan yang memiliki postur tubuh besar terutama di bagian panggul dan memiliki pantat yang besar, dengan delapan penari inti dan duapuluh penari pendukung. Ke delapan penari putri tersebut memiliki porsi gerak yang lebih banyak dibanding dengan dua puluh penari putri, sedangkan penari dua puluh tersebut bergerak hanya di bagian klimaks atau akhir karya tari ini. Tidak ada maksud khusus dalam pemilihan jumlah penari tersebut, hanya saja disesuaikan dengan kepentingan pola lantai 
dan pusat-pusat perhatian seperti 2 pusat perhatian atau focus on two point dan pola lantai seperti 2-6, 6-2, 1-7, 7-1 yaitu motif menuju kelompok delapan penari perempuan. Ke dua puluh penari tersebut juga memiliki peranan penting walau hanya bergerak pada saat klimaks, tidak ada maksud khusus menggunakan duapuluh penari, karena gerak pantat atau gerak megal-megol jika digerakkan secara rampak atau bersamaan dengan jumlah kelompok besar akan lebih menarik.

\section{Musik Tari}

Karya koreografi ini menggunakan iringan musik yang dikemas dalam bentuk MIDI (Musical Instrument Digital Interface) dengan tujuan untuk mempermudah selama proses latihan. Sedangkan konsep musik yang akan digunakan adalah genre tradisi yang dinamis, ritmis dan ilustratif dengan instrumen utama tabla atau kendang India. Banyak sekali aksen dalam karya tari ini sehingga instrumen jenis Tabla untuk memperkuat gerak tari.

\section{Rias dan Busana Tari}

Rias dalam karya koreografi ini menggunakan rias korektif, sedangkan busana yang digunakan berwarna menyerupai kulit dan sifatnya elastis agar bisa disesuaikan dengan bentuk tubuh penari, sehingga panggul akan terlihat jelas bentuknya.

\section{Pemanggungan}

a. Area Pementasan

Karya koreografi ini dilaksanakan di proscenium stage yang berada di Jurusan Seni Tari Fakultas Seni Pertunjukan ISI Yogyakarta.

\section{b. Ruang Pentas}

Ruang pentas yang digunakan adalah seluruh ruang yang ada di proscenium stage. titik tengah atau dead center merupakan ruang yang dominan digunakan penata.

\section{c. Tata Rupa Pentas}

Setting
Setting dalam karya koreografi ini menggunakan trap yang disusun menjadi level yang digunakan dalam bagian ending. Trap susun ini diletakkan di belakang tirai dan digunakan untuk tempat duduk atau gerak ditempat dari dua puluh penari yang disusun semenarik mungkin.

\section{d. Pencahayaan}

Karya koreografi ini bermain komposisi pola lantai penari dan setting panggung sehingga membutuhkan dukungan penyinaran yang baik.

\section{PROSES PENCIPTAAN TARI}

\section{A. Metode dan Tahapan Penciptaan}

\section{Metode Penciptaan}

\section{a. Tahap Eksplorasi}

Tahap pertama dalam melakukan eksplorasi ini adalah memperhatikan dan melihat cara orang berjalan di lingkungan kampus ISI Yogyakarta. Pada tanggal 18 Februari 2016 bersama semua penari melakukan eksplorasi di Proscenium Stage Jurusan Seni Tari Institut Seni Indonesia Yogyakarta. Penata memberikan arahan ke penari untuk melakukan berbagai kemungkinan gerak yang dimunculkan dari salah satu anggota tubuh yaitu panggul. Arahan untuk bergerak vibrasi diberikan ke Andini dan Tika, karena Andini dan Tika memiliki pantat yang lebih besar dibanding penari yang lainnya dan memiliki badan yang lebih berisi, sedangkan arahan untuk bergerak megal-megol atau pantat yang bergerak ke kanan dan ke kiri diberikan ke Yussi dan Manja karena merek berdua memiliki postur tubuh kurang lebih seperti penata. Dalam metode eksplorasi ini ditemukan gerak-gerak yang unik dan tidak wajar seperti vibrasi pantat yang bergerak hanya kanan saja atau kiri. Hal tersebut memunculkan kelucuan yang di akibatkan dari gerakan pantat vibrasi sebelah. 


\section{b. Tahap Improvisasi}

Proses tahap improvisasi ini dilakukan bersamaan dengan tahap eksplorasi, membebaskan ketubuhan dan berekspresi penari mengikuti arahan-arahan yang diberikan.

Improvisasi muncul bersamaan dengan eksplorasi ketika dengan penari latihan di Studio 1 Jurusan Seni Tari dan proscenium stage Jurusan Tari. Penata mencoba menggunakan musik suasana dangdut yang banyak mengandung unsur kendang serta musik-musik tarian belly dance, penata membiarkan penari untuk merespon musik, selain itu penata juga membebaskan penari untuk bergerak.

\section{c. Tahap Komposisi}

Proses komposisi "Sonyol MegalMegol" telah berjalan dengan baik karena sebelumnya telah melalui proses secara berurutan dan sesuai dengan yang diinginkan hingga pada saat mengkomposisi hanya menyusun dan menata saja, materi gerak yang sudah tersedia, pada tahap ini terkadang dirasa sulit jika satu penari saja tidak dapat hadir dalam latihan. Hal ini dirasakan sulit karena komposisi dengan penari yang tidak lengkap kurang terlihat dari gerak penari dan tidak bisa memunculkan imajinasi bagi penata. Selain itu, ketidak hadiran penari juga berpengaruh terhadap imajinasi penari dalam menggerakkan materi gerak yang diberikan.Selain berimajinasi, penari juga terasa kurang untuk merasakan, menghayati dan mengkhayalkan konsep di setiap adegan. Penata mencoba bercerita kembali maksud tiap gerak maupun adegan ke penari pada saat waktu istirahat agar dalam melakukan gerak yang sudah dikomposisikan ataupun berimajinasi tidak terlalu jauh dari yang diharapkan penata.

\section{d. Tahap Evaluasi}

Evaluasi bisa dikatakan sebagai penilaian selama proses karya. Maksud dari penilaian di sini adalah penilaian dari penata mengenai proses semua pendukung karya seperti penari, musik, setting, properti dan semua pendukung yang terlibat dalam karya koreografi ini. Tujuan diadakannya evaluasi ini untuk membenahi kesalahan-kesalahan ataupun kekurangan-kekurangan selama proses latihan agar dapat dibenahi sesuai dengan koreografi yang diinginkan.

\section{Tahapan Penciptaan}

\section{a. Tahapan Awal}

\section{Penetapan Ide dan Tema}

Ide karya koreografi ini berawal dari melihat dan memperhatikan orang ketika berjalan hal ini menjadi menarik karena terjadi keunikan gerak yaitu yang biasa disebut dengan gerak megal-megol atau pantat yang bergerak ke kanan dan ke kiri. Bermodalkan postur tubuh yang sangat tidak proposional atau panggul terlalu besar dan mempunyai keunikan yang orang lain belum tentu bisa menggerakan yaitu pergerakan otot pantat yang disebut muskulus gluteus maksimus.

Tema dalam karya koreografi ini adalah pengolahan gerak patah-patah dan melingkar pada panggul. Penetapan tema ini muncul dikarenakan gerak patah-patah dan melingkar lebih dominan dalam karya tari ini.

2. Pemilihan dan Penetapan Penari

Dalam pemilihan penari penata mempunyai kriteria khusus, tubuh yang tidak proposional atau panggul yang terlalu besar menjadi pengangan awal untuk memilih seorang penari. Penata juga melihat penari yang mau berdiskusi dan berproses bersama agar dalam proses karya koreografi ini bisa menyampaikan ide-ide atau masukan dari para penari.

\section{Pemilihan dan Penetapan Pemusik}

Dalam penetapan penata musik, penata tidak mempunyai kriteria khusus dalam hal bermusik tetapi penata memilih penata musik berdasarkan kemampuan dalam membuat jenis musik MIDI (Musical Instrument Digital Interface), pengalaman membuat musik, dan kinerja saat berproses. Penata musik dalam karya koreografi ini adalah Danang Rajiev 
Setyadi atau kerap disapa dengan nama Rajiev. Rajiev merupakan salah satu seniman musik tradisi yang pernah menempuh studi di jurusan Karawitan ISI Yogyakarta. Beliau sudah beberapa kali menggarap musik sebagai iringan tari dalam format live dan beliau tidak pernah menggarap musik dengan format MIDI, maka dari itu Beliau mengajak Sulis untuk membantu menggarap musik dalam format MIDI

\section{B. Paparan Hasil Penciptaan}

\section{Urutan Penyajian Tari}

\section{a. Introduksi}

Ke tujuh penari berada tepat di balik tirai dengan posisi membelakangi penonton dan berpose seperti gerakan rukuk sewaktu sholat dengan kepala melihat keatas, ketika musik mulai bertempo cepat kemudian tirai dibuka. Permainan ruang yang awalnya sempit dan jauh kemudian menjadi luas hadir pada bagian ini. Pada bagian introduksi ini ke tujuh penari melakukan gerak rampak yang kemudian pecah menjadi satu garis horisontal, transisi gerak yang dilakukan adalah gerakan vibrasi pantat yang dilakukan secara berjalan dan membentuk focus on three point. Penari Kristian, Mia dan Nia berada di down center membentuk pola lantai segitiga dengan level yang tinggi sedangkan Manja, Adnini berada di up left dan Tika, Yussi berada di up right dengan level rendah. Ruang Gerak yang dilakukan Manja, Andini, Tika dan Yussi lebih luas dari ruang gerak yang dilakukan tiga penari. Setelah sama-sama bergerak kemudian ketujuh penari melakukan gerakan megalmegol dengan locomotor movement (berpindah tempat) menuju ke down center dengan membentuk pola lantai $\mathrm{V}$ kemudian menggerakan motif putar kepala yang diikuti gerak panggul secara bergantian, penari Manja dan Mia pecah dan berada di down left penari Yussi dan Nia pecah dan berpindah di down right sedangkan penati Tika, Andini dan Kristian tidak berpindah tempat tetap berada di down center membentuk segitiga kecil. Setelah ketujuh penari melakukan gerak rampak kemudisn membentuk pola lantai horizontal tepat di depan backdrop.

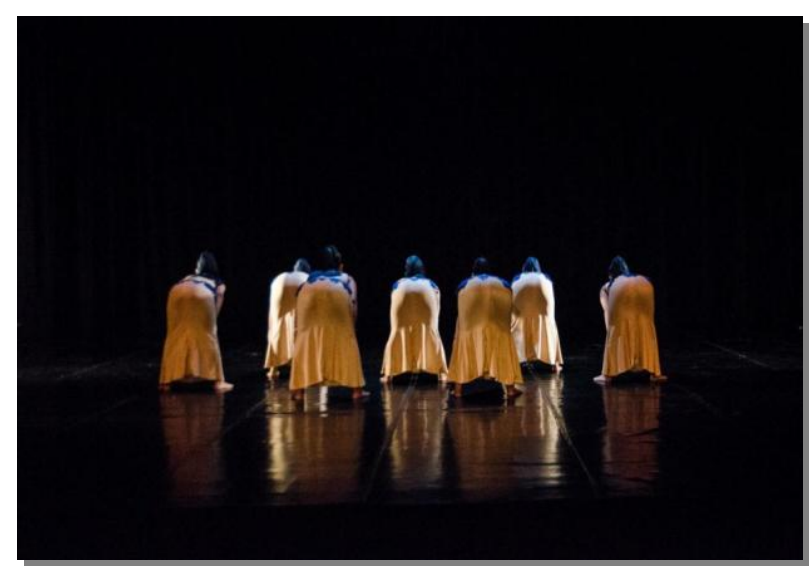

Gambar 2. Sikap awal adegan introduksi (foto: Ari, 2016)

\section{b. Adegan I}

Perbedaan adegan 1 dengan introduksi berada di musik, musik introduksi lebih ritmis dan banyak aksen sedangkan setelah memasuki adegan 1 musik yang di gunakan lebih ilustrasi, atau menari dengan menggunakan rasa. Penari Tika, Kristian, Mia dan Andini berada di down right membentu pola lantai layang-layang dengan pose nungging membelakangi penonton sedangkan penari Yussi, Nia dan Manja membentuk pola lantai segitiga berada di down left. Kemudian Nia berpindah tempat menuju up left dengan bergerak meliyuk dominan panggul, disusul Yussi dan Manja menuju up left dengan bergerak mengangkat kaki sehingga panggul terlihat menonjol. Kemudian ke tujuh penari bergerak menuju center menjadi pola lantai setengah lingkaran, setelah itu pecah dan menjadi tiga fokus dan bergerak secara gantian, penari Tika, Yussi dan Nia berada di up right, penari Kristian dan Mia berada di center sedangakn penari Manja dan Andini berada di up left. Penata membagi tiga fokus dengan pose pantat menonjol, diantaranya Kristian dengan Mia, Manja dengan Andini dan Tika,Yussi dan Nia. Pose pantat menonjol ini dilakukan dengan locomotor movement dan saling mengisi ruang. 


\section{c. Adegan II}

Bagian ini diawali dengan menggerakan motif sonyol megal-megol dengan ke tujuh penari menyebar mengisi ruang kosong Andi dan Mia berada di level rendah di upround sedangkan Tika, Nia, Kristian, Manja dan Yussi mengisi ruang kosong. Setelah bergerak motif sonyol megalmegol ketujuh penari menyatu membentuk pola lantai satu garis horizontal dan bergerak rampak dengan menggerakan motif Hak e Hok ya dan pecah menjadi dua garis horizontal. Penari Nia dan Tika menuju down center diikuti Mia, Andini, Yussi, Manja dan Kristian menjadi dua garis vertikal, setelah itu pecah membetuk pola lantai V. Yussi dan Kristian bergerak mendekati Manja yang berada di depan dengan locomotor movement sehingga mereka bertiga menjadi sejajar dan bergerak rampak dan level rendah. Tika, Nia, Andini dan Mia menyusul kedepan ketiga penari dengan bergerak berpindah tempat, ketujuh penari yang sudah berada di uprond bergerak bersamaan dengan pola lantai A namun menyempit. Kemudian ketujuh penari bergerak berpindah dan membentuk pola lantai satu garis vertikal tepat di center. Setelah menjadi satu garis vertical ketujuh penari pecah dan membentu tiga fokus. Yussi, Andini, dan Nia berada di down center membentuk pola lantai segitiga, Tika dengan Kristian berada di up right bergerak bersamaan dengan Manja dan Mia yang berada di up left. Manja dan Nia mendekati Tika yang berada di up right dengan bergerak berpindah sedangkan Yussi, Mia, Kristian dan Andini menuju ke down right bergerak meliyuk bermaksud menjemput Sekar. Ke delapan penari menuju up left dengan bergerak berjalan dan berpindah kemudian menjadi satu garis horizontal kemudian pecah menuju center dengan pola lantai A dan penari Yussi dengan Sekar berada di tengah menggerakan motif sya la la la. Kemudian ketujuh penari bergerak menuju pit orchestra dan meninggalkan Sekar di center.

\section{d. Ending}

Bagian akhir karya tari ini di awali dengan tiga fokus, fokus pertama Sekar menari tunggal di up center dengan motif-motif gerak panggul dan tirai menutup. Fokus kedua penari Tika, Mia, dan Nia berada di pit orchestra sebelah kiri sedangkan Manja, Yussi, Andini dan Kristian berada di pit orchestra sebelah kanan. Ketiga fokus tersebut bergerak secara bergantian seperti tanya jawab, dan kembali lagi Sekar bergerak sendiri dengan motif gerak kedut pantat setelah itu tirai dibuka dan muncul rampak motif kedut pantat yang dilakukan oleh duapuluh penari.

\section{Deskripsi Motif Gerak}

\section{a. Motif Pantat Njedid}

Posisi dimulai dengan berdiri tegak hitungan satu dan dua tubuh kebawah sehingga bergerak seperti gerakan rukuk sewaktu sholat, posisi tangan memegang lutut hitungan tiga dan empat proses bergerak naik dengan dibantu liukan badan dan tubuh mendak secara tiba-tiba kemudian cengket hitungan lima dan enam pantat digerakkan ke kanan dan ke kiri hitungan tujuh dan delapan tubuh diputar hingga badan berdiri tegak.

\section{PENUTUP}

\section{A. Kesimpulan}

Karya tari Sonyol Megal-Megol adalah sebuah karya tari ciptaan baru yang merupakan hasil penuangan ide serta kreativitas penata tari, yang dilatarbelakangi dari gerakan panggul yang ketika berjalan akan terjadi gerakan yang disebut dalam istilah Jawa megal-megol, kemudian gerakan tersebut dikembangkan sehingga memperkaya pengolahan gerak. Karya tari ini disajikan dalam bentuk koreografi kelompok, didukung duapuluh delapan penari putri. Delapan orang penari inti, duapuluh penari pendukung. Musik pengiringnya menggunakan jenis musik MIDI (Musical Instrument Digital Interface). 


\section{B. Saran}

Karya koreografi ini jauh dari kata sempurna baik dari tulisan maupun karya, maka dari itu penata merasa butuh saran berupa kritik ataupun masukan demi kebaikan untuk penata sendiri maupun penikmat seni khususnya seni tari. Menjadi seorang koreografer juga bisa di katakan sebagai pemimpin, tidak hanya mengatur penari, tetapi unsur-unsur yang terdapat pada karya tari juga harus dipikirkan oleh koreografer. Manajemen dari seorang koreografer terntunya sangat berpengaruh terhadap proses maupun hasil dari karya tari tersebut.

\section{DAFTAR SUMBER ACUAN}

\section{A. Sumber Tertulis}

Hadi, Y. Sumandiyo. 2003, Aspek-Aspek Dasar Karya Tari Kelompok, Yogyakarta: Manthili,

\section{7, Kajian Tari Teks} dan Konteks, Pustaka Book Publisher, Yogyakarta.

.2011, Koreografi: Bentuk Teknik Isi, Yogyakarta: Cipta Media.

.2012, Seni Pertunjukan dan Masyarakat Penonton, Yogyakarta: BP ISI Yogyakarta

Hawkins, Alma M. 1998, Creating Trought Dance, diterjemahkan Y. Sumandiyo Hadi berjudul Mencipta Lewat Tari, 2003, Yogyakarta, Manthili.

Martono, Hendro. 2008, Sekelumit Ruang Pentas Modern dan Tradisi, Yogyakarta, Cipta Media.

2010, Mengenal Tata Cahaya Seni Pertunjukan, Yogyakarta: Cipta Media.
2012, Ruang Pertunjukan dan Ruang Berkesenian, Yogyakarta: Cipta Media.

Murgiyanto, Sal.1992 Koreografi. Jakarta: Pusat Pembukuan Departemen Pendidikan dan Kebudayaan

Setiadi. 2007, Anatomi \& Fisiologi Manusia, Yogyakarta: Graha Ilmu.

\section{B. Sumber Lisan}

1. Pangkuyhona, 34 tahun Yogyakarta 1982, berprofesi sebagai wirausahawan (alumni Sastra Jawa UNY) .

2. Rizky Fauziah, 29 tahun Yogyakarta, berprofesi sebagai dokter umum di rumah sakit Happy Land Medical Center

\section{Webtografi}

www.youtube.com

\section{Sumber Video}

-Video karya tari International Summer Bellydance Festival 2014

-Koreografi 3 "Sonyol" karya Sekar Ayu Oktaviana Sari 